\title{
Efficient sonochemical synthesis of thiazolidinones from piperonilamine
}

\author{
Juliano Bosenbecker, Daniela P. Gouvêa, Thayli R. Araujo, Venise A. Gouvêa, \\ Wilson Cunico
}

\author{
Núcleo de Química Aplicada (NuQuia), Departamento de Química Orgânica, UFPel, Pelotas, RS, Brazil \\ *wjcunico@yahoo.com.br
}

Keywords: thiazolidinones, piperonilamine, sonochemistry

\section{INTRODUCTION}

Thiazolidinones are important five-membered heterocycles that have valuable biological activities in the medicine chemistry ${ }^{1}$. Recently, we published an efficient, solvent free improved synthesis of 2 (alkyl/aryl)-3-arylamino-1,3 thiazolidin-4-ones from hydrazones. $^{2}$ In our research program, there is also an interest in improving the methodologies for the preparation of such heterocycles by non-traditional conditions like sonocatalysis. Ultrasound irradiation has been utilized to accelerate a number of synthetically useful reactions during the last few years. In continuation of our studies, the aim of this paper is the sonocatalysis synthesis of heterocyclic thiazolidinones from the cyclocondensation reaction of piperonilamine, arenealdehydes and mercaptoacetic acid.

\section{RESULTS AND DISCUSSION}

The conventional syntesis of thiazolidinones $\mathbf{5 a - k}$ is carried out with one equivalent of piperonylamine, one equivalent of arenealdehyde and three equivalents of mercaptoacetic acid for $16 \mathrm{~h}^{3}$ The study of reaction conditions in ultrasound irradiation for the preparation of compound $\mathbf{5 c}$ is summarized in Scheme 1 and the progress of reaction was monitored by GC analysis.

\section{Scheme 1}

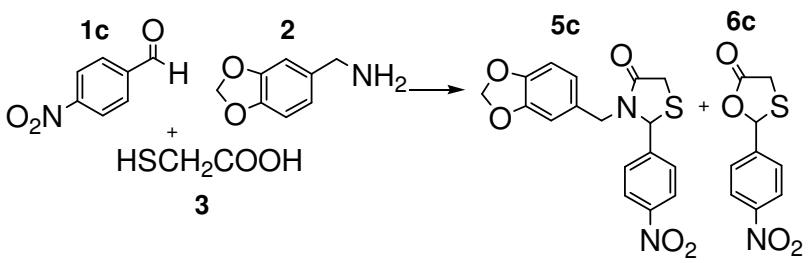

\begin{tabular}{lccc}
\hline Equimolar proportion & Yield & \multicolumn{2}{c}{ GC-Analyses (\%) } \\
\cline { 4 - 5 } amine:aldehyde:acid & $(\%)^{\mathrm{b}}$ & $\mathbf{5 c}$ & By-product \\
\hline $1: 1: 1$ & 62 & 68 & 20 \\
$1: 1: 3$ & 65 & 73 & 17 \\
$1: 2+3^{\mathrm{a}}$ & 100 & 42 & 48 \\
$1: 1+1^{\mathrm{a}}$ & 92 & 89 & - \\
$1: 1+3^{\mathrm{a}}$ & 85 & 88 & 4 \\
\hline${ }^{\mathrm{a}}-$ mercaptoacetic acid added after 2,5 $^{2}$ minutes. ${ }^{\mathrm{b}}$ - crude product $^{2}$ & \multicolumn{3}{c}{}
\end{tabular}

So, the thiazolidinones 5a-j were synthesized in good yields from the reaction of one equivalent of piperonilamine 2 and one equivalent of arenealdehydes 1a-j using ultrasound irradiation for 2.5 minutes. After this time, the mercaptoacetic acid 4 was added and the reactions were sonicated for more $2.5 \mathrm{~min}$. The structures of heterocycles $\mathbf{5 a - j}$ were confirmed by ${ }^{1} \mathrm{H},{ }^{13} \mathrm{C}$ NMR.

Scheme 2

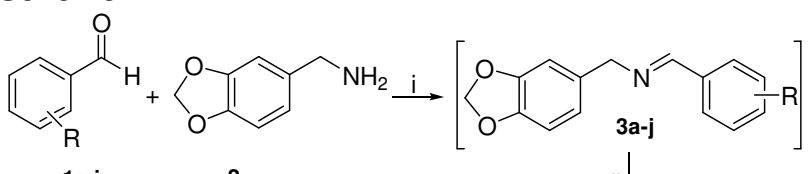

1a-j 2

i: toluene, ultrasonic irradiation, 2,5 min

ii: $\mathrm{HSCH}_{2} \mathrm{COOH}$ 4, ultrasonic irradiation, 2,5 min

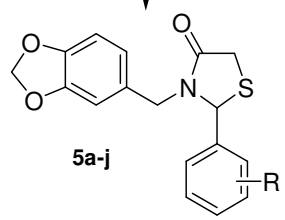

Table 1. Yields of thiazolidinones 5a-k

\begin{tabular}{|c|c|c|c|}
\hline Product & $\mathrm{R}$ & $\begin{array}{c}\text { Ultrasound yield } \\
(\%)^{\mathrm{a}}\end{array}$ & $\begin{array}{l}\text { Conventional } \\
\text { yield }(\%)^{b}\end{array}$ \\
\hline $5 a$ & $2-\mathrm{NO}_{2}$ & 82 & 69 \\
\hline $5 b$ & $3-\mathrm{NO}_{2}$ & 85 & 77 \\
\hline $5 c$ & $4-\mathrm{NO}_{2}$ & 92 & 90 \\
\hline $5 d$ & $2-F$ & 65 & 71 \\
\hline $5 e$ & $3-F$ & 60 & 75 \\
\hline $5 f$ & $4-F$ & 70 & 51 \\
\hline $5 g$ & $2-\mathrm{OCH}_{3}$ & 66 & 65 \\
\hline $5 h$ & $3-\mathrm{OCH}_{3}$ & 74 & 84 \\
\hline $5 i$ & $4-\mathrm{OCH}_{3}$ & 72 & 81 \\
\hline $5 \mathbf{j}$ & $4-\mathrm{CN}$ & 79 & 70 \\
\hline
\end{tabular}

\section{CONCLUSION}

The sonochemistry procedure can be used as a replacement for conventional thermal synthetic methodology, allowing rapid access to a wide range of thiazolidinones and reducing the reaction times.

\section{ACKNOWLEDGEMENTS}

UFPEL, IFSUL, Farmanguinhos, CNPq, CAPES.

\section{REFERENCES}

${ }^{1}$ W. Cunico, C.R.B. Gomes, W.T. Vellasco Jr., Mini-Rev. Org. Chem. 5 (2008) 336.

P.D. Neuenfeldt, B.B. Drawantz, G.M. Siqueira, C.R.B. Gomes, S.M.S.V. Wardell, A.F.C. Flores, W. Cunico, Tetrahedron Lett. 51 (2010) 3106

${ }^{3}$ C.R.B.Gomes, M.Moreth, V.Facchinetti, M.V.N. de Souza, W T. Vellasco Jr., M.C.S. Lourenço, W. Cunico, Lett Drug Des. Discov. 7 (2010) 353. 